Research Paper: Gerotarget

\title{
Virtual screening, optimization, and identification of a novel specific PTP-MEG2 Inhibitor with potential therapy for T2DM
}

\author{
Meiyan Wang ${ }^{1, *}$, Xiaobo $\mathrm{Li}^{1,2, *}$, Lei Dong ${ }^{2, *}$, Xiubo Chen ${ }^{3}$, Weiren $\mathrm{Xu}^{4}$ and Runling \\ Wang ${ }^{1}$ \\ ${ }^{1}$ Tianjin Key Laboratory on Technologies Enabling Development of Clinical Therapeutics and Diagnostics (Theranostics), \\ School of Pharmacy, Tianjin Medical University, Tianjin, China \\ 2 Department of Pediatrics, Emory University School of Medicine, Atlanta, GA, USA \\ ${ }^{3}$ Tianjin Medical University Eye Hospital, Tianjin, China \\ ${ }^{4}$ Tianjin Key Laboratory of Molecular Design and Drug Discovery, Tianjin Institute of Pharmaceutical Research, Tianjin, China \\ * These authors have contributed equally to this work
}

Correspondence to: Runling Wang, email: wangrunling@tijmu.edu.cn

Keywords: PTP-MEG2 inhibitor; core hopping; diabetes; selectivity; molecular dynamics simulation; Gerotarget

Received: March 22, $2016 \quad$ Accepted: June 03, 2016

Published: June 30, 2016

\section{ABSTRACT}

Megakaryocyte protein tyrosine phosphatase 2 (PTP-MEG2) is a tyrosine phosphatase expressed in megakaryocytic cells, and causes insulin sensitization when down regulated. Therefore, specific inhibitors of PTP-MEG2 are potential candidates for novel Type 2 Diabetes (T2DM) therapy. In this study, we discovered PTP-MEG2 inhibitors using high throughput and virtual screening (HTS/VS) and structural optimization in silicon. Eight compound-candidates were identified from the interactions with PTP-MEG2, protein tyrosine phosphatase 1B (PTP1B) and T cell protein tyrosine phosphatase (TCPTP). Results from enzymatic assays show compounds $4 a$ and $4 b$ inhibited PTP-MEG2 activity with an IC50 of $3.2 \mu \mathrm{M}$ and 4.3 $\mu \mathrm{M}$, respectively. Further, they showed a 7.5 and 5.5 fold change against PTP1B and TCPTP, respectively. We propose compounds $4 a$ and $4 b$ are PTP-MEG2 inhibitors with potential therapeutic use in T2DM treatment.

\section{INTRODUCTION}

Protein tyrosine phosphatases (PTPs) are enzymes that remove phosphate groups from substrates, and contain a highly conserved active site motif $\mathrm{C}(\mathrm{X})_{5} \mathrm{R}$. PTPs play important roles in signaling transduction of intra- and inter-cellular functions associated with cell growth, proliferation, differentiation, survival, apoptosis, adhesion, and motility [1-4]. Megakaryocyte protein tyrosine phosphatase 2 (PTP-MEG2), encoded by protein tyrosine phosphatase non-receptor type 9 (PTPN9) [5, 6], was originally cloned from human endothelial cells and megakaryocytes. Reduction of PTP-MEG2 in hepatic cells increases insulin sensitivity [7]. Therefore, PTP-MEG2 inhibitors with high selectivity and activity represent potentially efficient therapies for Type 2 Diabetes (T2DM).

Classical strategies for inhibitor discovery were designed to identify compounds that target the catalytic site of enzymes. However, acquiring specific PTPMEG2 inhibitors has been problematic given active sites typically have high sequence homology in the PTP super family (Table S1) $[8,9]$. According to multiple sequence alignments and conformational superposition of PTPMEG2 with other PTPs, previous research described an extended binding gorge from the active site as a selective binding pocket that helps identify PTP-MEG2 inhibitors [4].

In this study, we used scaffold-based strategies to discover novel PTP-MEG2 inhibitors in silicon, and applied enzymatic assays in vitro to evaluate inhibitory activities. ZINC01433265 was screened from the drug-like molecular database through high throughput and virtual screening (HTS/VS) as a lead-compound for further optimization. Eight structure-candidates were identified as potential PTP-MEG2 inhibitors via "core-hopping". Compounds $4 \mathrm{a}$ and $4 \mathrm{~b}$ were chosen to synthesize for enzymatic assay based on the binding affinity with various PTPs and their chemical structure. Our results show $4 \mathrm{a}$ and $4 \mathrm{~b}$ inhibited the activity of PTP-MEG2 with IC50 of $3.2 \mu \mathrm{M}$ and $4.3 \mu \mathrm{M}$, respectively. 
Table 1: The docking scores and predicted ADME properties of 8 ZINC01433265 derivatives

\begin{tabular}{|c|c|c|c|c|c|c|c|c|}
\hline \multirow{2}{*}{ Rank } & \multirow{2}{*}{ No. } & \multicolumn{3}{|c|}{ Docking scores(Kcal/mol) } & \multicolumn{4}{|c|}{ Predicted ADME properties } \\
\hline & & PTP-MEG2 & PTP1B & TCPTP & $\mathbf{P S A}^{\mathbf{a}}$ & $\operatorname{logPo} / \mathbf{w}^{b}$ & $\log S^{c}$ & PMDCK $^{\mathrm{d}}$ \\
\hline 1 & $4 a$ & -9.67 & -1.91 & -3.26 & 106 & 5.4 & -6.0 & 730.4 \\
\hline 2 & $4 b$ & -9.58 & -1.34 & -2.89 & 183 & 5.8 & -6.2 & 1282.7 \\
\hline 3 & $4 c$ & -9.56 & -1.60 & -2.11 & 194 & 6.0 & -6.6 & 1232.8 \\
\hline 4 & 4d & -9.44 & -1.10 & -1.34 & 136 & 5.4 & -6.1 & 713.6 \\
\hline 5 & $4 \mathrm{e}$ & -9.34 & -1.75 & -1.24 & 167 & 5.3 & -5.8 & 908.6 \\
\hline 6 & $4 f$ & -9.14 & -1.51 & -1.10 & 144 & 5.4 & -6.0 & 502.4 \\
\hline 7 & $4 g$ & -9.13 & -1.53 & -1.06 & 135 & 5.2 & -6.9 & 1254.3 \\
\hline 8 & $4 h$ & -9.13 & -1.66 & -1.06 & 165 & 5.7 & -5.3 & 1232.5 \\
\hline
\end{tabular}

a The van der Waals surface area of polar nitrogen and oxygen atoms (7.0 to 200.0).

${ }^{\mathrm{b}}$ The predicted octanol/water partition coefficient ( -2.0 to 6.5$)$.

c The predicted aqueous solubility, where $\mathrm{S}\left(\mathrm{mol} \mathrm{dm}^{-3}\right)$ is the concentration of the solute in a saturated solution that is in equilibrium with the crystalline solid ( -6.5 to 0.5$)$.

${ }^{\mathrm{d}}$ The apparent MDCK permeability (nm/s); MDCK cells are considered as a good mimic for the blood brain barrier. QikProp predictions are for non-active transport $(<25$ poor; $>500$ great).

\section{RESULTS}

\section{Virtual screening and core-hopping}

Structure-based virtual screening in ZINC drug-like database was performed in silicon. According to virtual screening results, molecule ZINC01433265 (Figure 1) was selected as the PTP-MEG2 inhibitor given it fit neatly into the docking pocket of PTP-MEG2 and formed hydrogen bonding with Arg311. However, we realized ZINC01433265 was too small to occupy the entire space of that pocket. Therefore, the small molecule $4 \mathrm{a}$ needed to be extended to reach the other side of the catalytic pocket by core-hopping of Schrodinger in silicon. The structures of the top 8 ZINC01433265 derivatives obtained from core-hopping are listed in Figure 1 and their docking scores are ranked in Table 1.

\section{ADME prediction}

The results of ADME prediction obtained from Qikprop of the 8 candidates are shown in Table 1. PSA, $\log \mathrm{Po} / \mathrm{w}, \operatorname{logS}$, and PMDCK were within the acceptable ranges for further drug discovery.

\section{Synthesis of $4 a$ and $4 b$}

The synthetic routes of compounds $4 \mathrm{a}$ and $4 \mathrm{~b}$ are shown in Figure 2. Naphthalen-1-amine reacted with chloroacetyl chloride treated with $\mathrm{K}_{2} \mathrm{CO}_{3}$ as the catalyst in acetone to produce $3 \mathrm{a}$. Compound $3 \mathrm{a}$ was mixed with benzo[d]thiazole-2-thiol in DMF with $\mathrm{K}_{2} \mathrm{CO}_{3}$ and $\mathrm{KI}$ catalyst for 3 hours to generate compound $4 \mathrm{a}$. Compound $4 \mathrm{~b}$ was synthesized using the same method above:
2-(benzo[d]thiazol-2-ylthio)-N-(naphthalen1-yl)acetamide(4a) A white solid with the following characteristics: $71.7 \%$ yield; ${ }^{1} \mathrm{H}-\mathrm{NMR}(\mathrm{CDCl} 3,400 \mathrm{MHz})$ : $\delta 10.05$ (br s, $1 \mathrm{H}), 8.14(\mathrm{~d}, J=8.0 \mathrm{~Hz}, 1 \mathrm{H}), 8.00(\mathrm{~d}, J=8.0$ $\mathrm{Hz}, 1 \mathrm{H}), 7.95(\mathrm{~d}, J=8.0 \mathrm{~Hz}, 1 \mathrm{H}), 7.87-7.80(\mathrm{~m}, 2 \mathrm{H}), 7.65$ (d, $J=8.0 \mathrm{~Hz}, 1 \mathrm{H}), 7.52-7.30(\mathrm{~m}, 5 \mathrm{H}), 4.26(\mathrm{~s}, 2 \mathrm{H})$.

4-(benzo[d]thiazol-2-ylthio)-N-(naphthalen-1-

yl)butanamide(4b) A white solid with the following characteristics: $16.9 \%$ yield; ${ }^{1} \mathrm{H}-\mathrm{NMR}(400 \mathrm{MHz}, \mathrm{CDCl} 3)$ : $\delta 8.21$ (br s, $1 \mathrm{H}), 7.88-7.86(\mathrm{~m}, 3 \mathrm{H}), 7.74-7.72(\mathrm{~m}, 2 \mathrm{H})$, $7.95(\mathrm{~d}, J=8.0 \mathrm{~Hz}, 1 \mathrm{H}), 7.54-7.38(\mathrm{~m}, 3 \mathrm{H}), 7.36-7.21(\mathrm{~m}$, $2 \mathrm{H}), 3.58(\mathrm{t}, J=6.8 \mathrm{~Hz}, 2 \mathrm{H}), 2.75(\mathrm{t}, J=6.8 \mathrm{~Hz}, 2 \mathrm{H}), 2.36$ $(\mathrm{m}, 2 \mathrm{H})$.

\section{Enzymatic assays}

We found compound 4a inhibited PTP-MEG2 with an IC50 of $3.2 \mu \mathrm{M}$, approximately 7.5 fold higher compared with PTP1B and TCPTP. Compound 4b inhibited PTP-MEG2 with an IC50 of $4.3 \mu \mathrm{M}, 5.5$ fold higher compared with PTP1B and TCPTP.

\section{Drug-protein interaction}

The PTP-MEG2 crystal structure shows the ligand binding domain is surrounded by P-loop (residues514-521), a pTyr recognition loop (residues331-338) and a hydrophobic patch formed by residues Pro315, Phe319, Pro337, and Phe556 (Figure 3 ). We found the hydrophobic patch was unique and positioned in close proximity to the second aryl phosphate binding site, originally identified in PTP1B. In addition, results show Gly334, located in pTyr loop, was also unique for PTP-MEG2. 
Table 2: PTP-MEG2, PTP1B and TCPTP inhibitory activities of compounds $4 \mathrm{a}$ and $4 \mathrm{~b}$.

\begin{tabular}{|l|l|l|l|}
\hline \multirow{2}{*}{ No. } & \multicolumn{3}{|l|}{$\mathrm{IC}_{50}(\mu \mathrm{M})$} \\
\cline { 2 - 4 } & PTP-MEG2 & PTP1B & TCPTP \\
\hline $4 \mathrm{a}$ & 3.2 & $>25$ & $>25$ \\
\hline $4 \mathrm{~b}$ & 4.3 & $>25$ & $>25$ \\
\hline
\end{tabular}

\section{Binding energy}

Binding energy describes van der Waals interactions and shot range electrostatic interactions between the ligand and receptor. We show the top 10 residues, forming binding energies tightly with $4 \mathrm{a}$ within a radius of 11 $\AA$ of the ligand, of PTP-MEG2 (red), TCPTP (purple) and PTP1B (blue) in (Figure 4). Results show the drugprotein binding energy in PTP-MEG2-4a system was significantly higher compared with TCPTP-4a and
PTP1B-4a, indicating compound 4a has higher affinity with PTP-MEG2. We found Asp335, the chief mediated residue located on pTyr recognition loop, contributed $-14.1 \mathrm{kcal} / \mathrm{mol}$ to the binding energy in the PTP-MEG24a system. In addition, we show other key residues, including Tyr333 (-11.9 kcal/mol) and Val336 (-10.0 kcal/ mol), formed steady hydrogen bonding and van der Waals with compound $4 \mathrm{a}$ during the simulation. Further, we found other $\mathrm{H}$-bonds between the benzo[d]thiazole ring of compound 4a and Arg311. Finally, at the other side of the binding area, the contribution of the characteristic PTPMEG2 residues related to PTP-MEG2 specificity were Phe556 (-12.5 kcal/mol), Pro315 (-12.0 kcal/mol) and Phe319 (-10.0 kcal/mol) (Figure 4).<smiles></smiles><smiles>O=C(CSc1nc2ccccc2s1)Nc1cccc2ccccc12</smiles>

$4 a$<smiles>O=C(CSc1nc2ccccc2s1)Nc1cccc(F)c1F</smiles>

$4 \mathrm{e}$

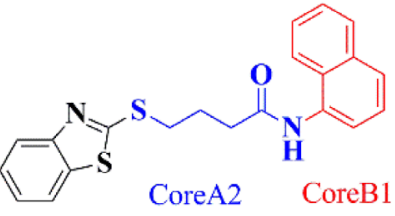

$4 b$

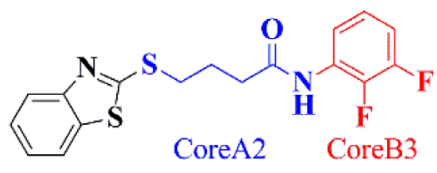

$4 \mathbf{f}$

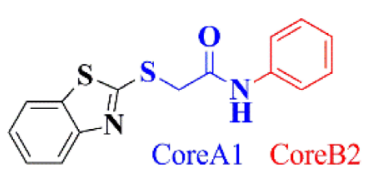

$4 \mathrm{c}$

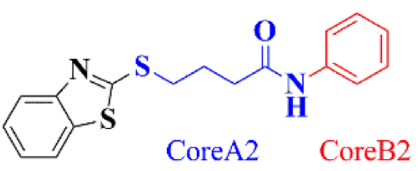

$4 d$

Figure 1: ZINC01433265 derivatives with high docking scores generated by core hopping.

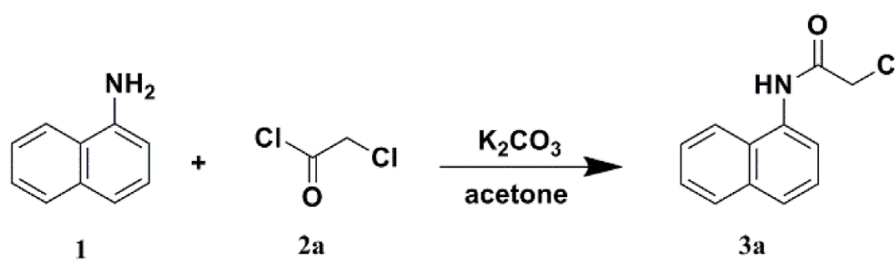

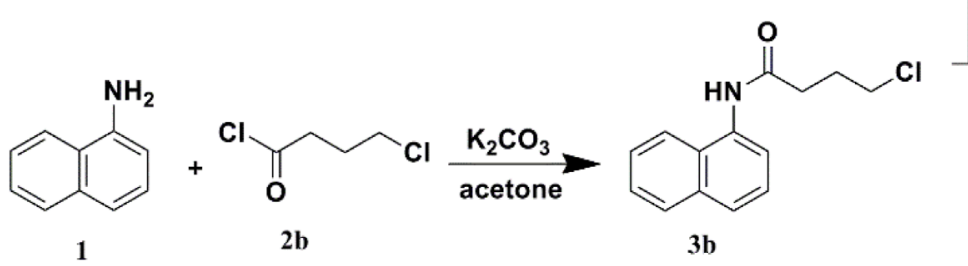

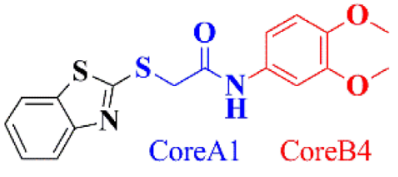

$4 \mathrm{~g}$

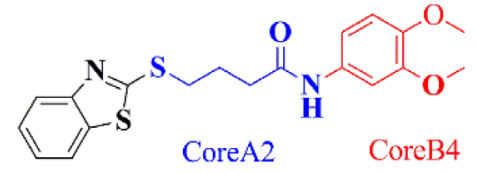

$4 h$

$2 b$

3b

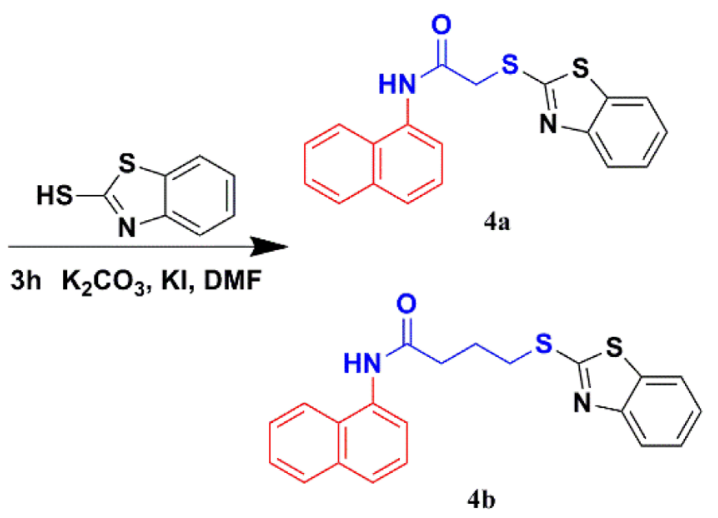

Figure 2: Synthetic routes of compounds $4 \mathrm{a}$ and $4 \mathrm{~b}$. 


\section{DISCUSSION}

Given that the PTP active site is highly conserved, identifying selective PTP inhibitors that bind to the pTyrbinding cleft is challenging. The PTP active site is highly charged to accommodate the pTyr substrate. Therefore, most existing PTP inhibitors are also highly polar compounds and exhibit poor bioavailability, which do not readily cross cell membranes.

In this study, we discovered PTP-MEG2 inhibitors using HTS/VS and structural optimization in silicon. Eight compound-candidates were identified from the interactions with PTP-MEG2, PTP1B, and TCPTP. Results from enzymatic assays show $4 \mathrm{a}$ and $4 \mathrm{~b}$ inhibited PTP-MEG2 activity with an IC50 of $3.2 \mu \mathrm{M}$ and $4.3 \mu \mathrm{M}$, respectively (Figure S1). In addition, we confirmed that PTP inhibitor potency and selectivity was achieved by targeting peripheral residues other than the active site.

We also show the PTP-MEG2 crystal structure of the ligand binding domain is surrounded by P-loop, pTyr recognition loop, and a hydrophobic patch (Figure 3). At the P-loop position, core B1 of compound 4a stretched

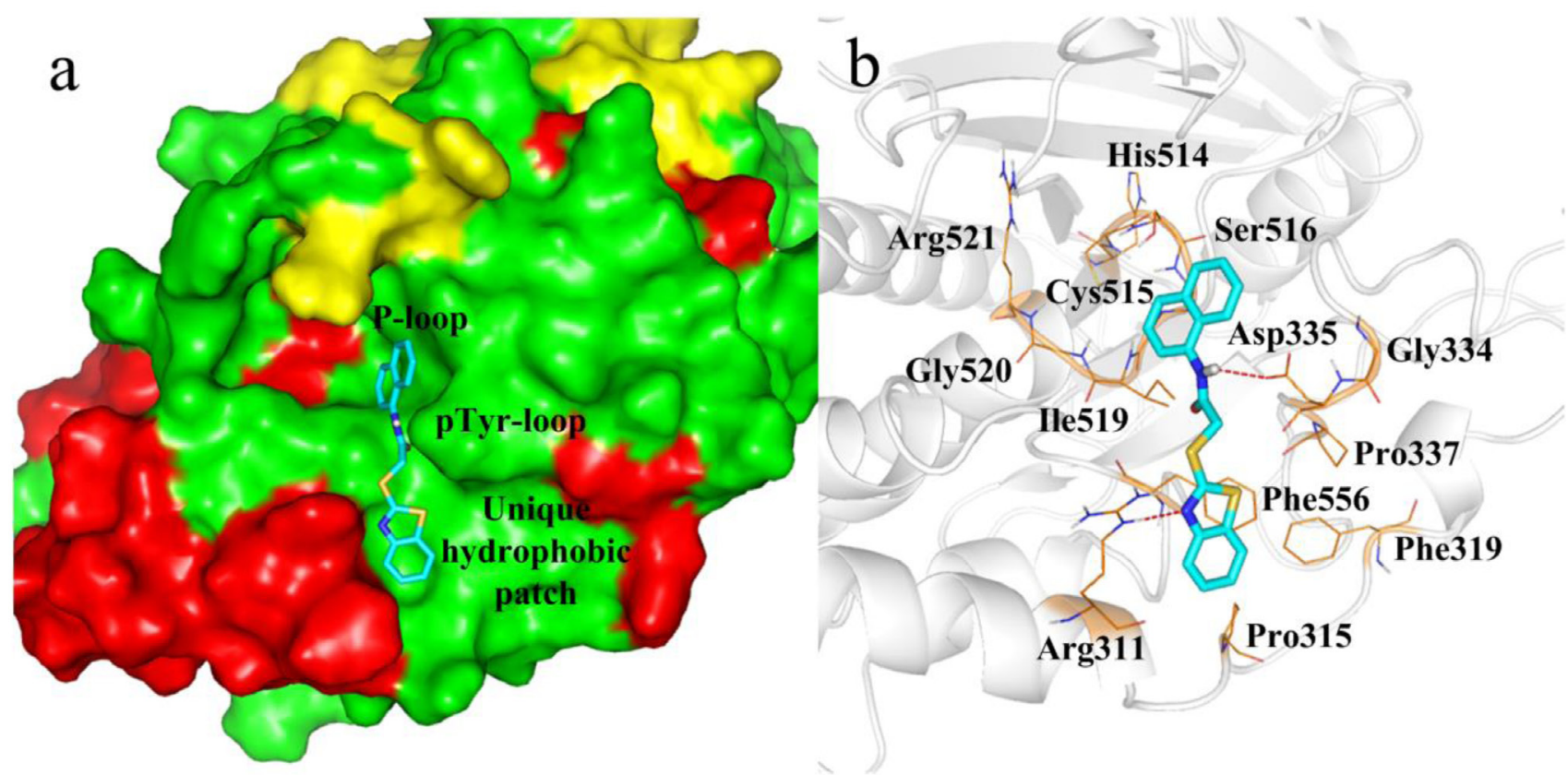

Figure 3: Docking of compound 4a with PTP-MEG2. a. Surface representation of PTP-MEG2 in complex with 4a. b. Docking interactions of compound 4a with PTP-MEG2 active site. The H-bond interactions between PTP-MEG2 and compound 4a are shown as red dashed lines.
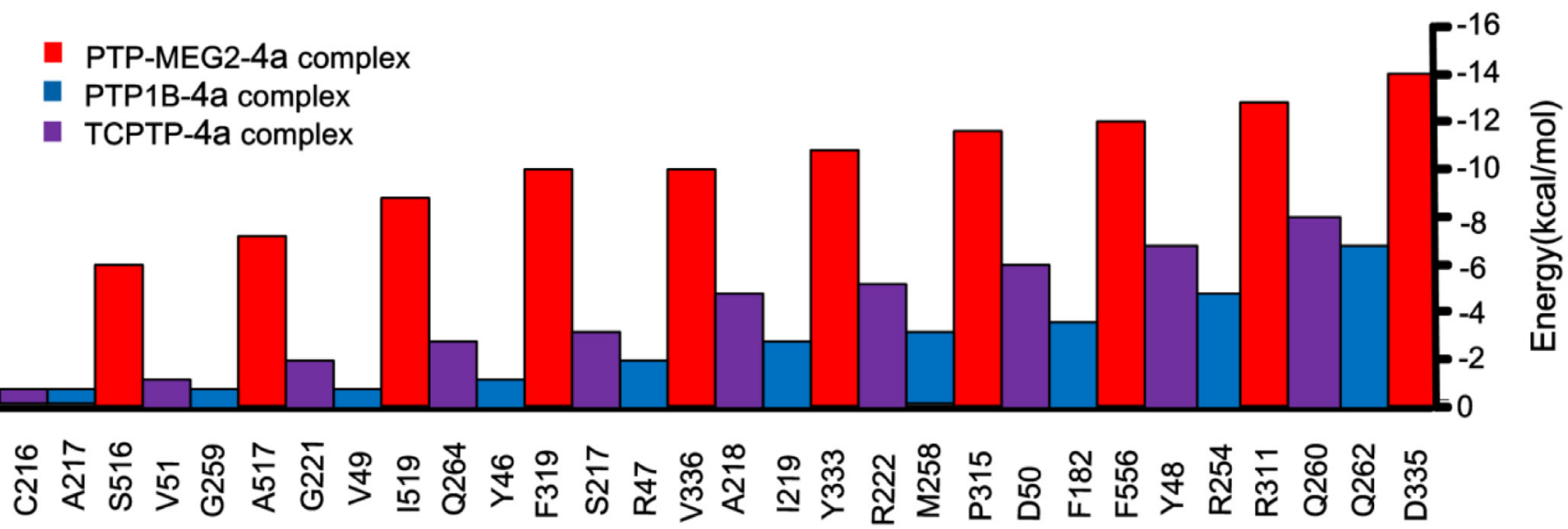

\section{Rank of Energy contrbuition}

Figure 4: The interaction energies of top 10 pairwise residues of the complex formed by PTP-MEG2 (red), PTP1B (blue), and TCPTP (purple) with compound 4a. 
into the catalytic pocket of PTP-MEG2 (Figure 3a). However, core B1 was too small to perfectly fit the pocket. We plan to further optimized B1 to identify compounds with higher affinity to PTP-MEG2. At the pTyr-loop position, compound 4a formed one H-bond with Asp335 and van der Waals interaction with Tyr333. Although Tyr333 and Asp335 in the pTyr-loop were conserved among the PTPs, this intense interaction may account for the PTP-MEG2 inhibitory activity of compound 4a. In addition, the H-bond formed by the benzo[d] thiazole ring of compound $4 \mathrm{a}$ and $\operatorname{Arg} 311$ enhanced the binding affinity between PTP-MEG2 and compound 4a (Figure 3b). The hydrophobic binding pocket formed by Pro315, Phe319, Pro337 and Phe556 is unique to PTP-MEG2 compared with other PTPs. The benzo[d] thiazol ring of compound $4 a$ was engaged in strong aromatic stacking interactions with residues Pro315, Phe319 and Phe556 (Figure 3b), which was favorable to the PTP-MEG2 selectivity of 4a.

Compared with the binding energies in PTP-MEG24a system, compound $4 \mathrm{a}$ had lower binding interactions with TCPTP and PTP1B (Figure 4). This finding suggests compound $4 \mathrm{a}$ is a potential candidate for PTP-MEG2 inhibition with high selectivity.

In summary, eight novel ZINC01433265-based PTP-MEG2 inhibitors with high docking scores were designed by the core-hopping method. After synthesis and enzymatic assays, compound $4 \mathrm{a}$ exhibited significant PTP-MEG2 selectivity $(3.2 \mu \mathrm{M})$ over the two high homologous proteins TCPTP $(>25 \mu \mathrm{M})$ and PTP1B $(>25$ $\mu \mathrm{M})$. Molecular dynamics simulation results show $4 \mathrm{a}$ bound more steadily to PTP-MEG2 active pocket and formed stronger binding interaction with key residues of PTP-MEG2 compared with TCPTP or PTP1B. Therefore, compound $4 \mathrm{a}$ should be considered a potent and specific inhibitor against PTP-MEG2 and a potential therapeutic for T2DM.

\section{MATERIALS AND METHODS}

The crystal structures of PTP-MEG2 (PDB ID: 4GE6) $[4,10]$ and other PTPs were downloaded from the Protein Data Bank (PDB) of RCSB.org [11, 12].

\section{Virtual screening}

Structure-based virtual screening in ZINC druglike database was performed in silicon. The structure database was prepared by Schrödinger's LigPrep 2.3 and virtually screened using Schrödinger's Glide 5.5, which incorporated Maestro 9.2 of RHEL 5.0. The docking pocket of PTP-MEG2 for virtual screening was identified by the Receptor Grid-generation tool of Schrödinger, a grid within $5 \AA$ from original ligand (B26) in its co-crystal structure (PDB ID: 4GE6).

The increased selectivity of novel inhibitors was introduced in several continuous stages of scaffold optimization by a core-hopping [13, 14] program embedded in Schrödinger Suite 2012. ZINC fragments database[15] was used. All investigated compound candidates were docked into the binding pocket through the flexible docking model. According to the docking scores $[16,17]$, top candidates with rational structures were classified as potential PTP-MEG2 inhibitors for further study.

\section{ADME prediction}

The "QikProp"[18] module predicted ADME (absorption, distribution, metabolism, and excretion) properties. The parameters of the partition coefficient (QP $\log \mathrm{Po} / \mathrm{w})$, van der Waals surface area of polar nitrogen and oxygen atoms (PSA), predicted aqueous solubility (QP $\operatorname{logS}$ ), and apparent MDCK permeability (QPP MDCK) were used in the QikProp to evaluate the acceptability of the compounds [19].

\section{Chemistry}

All starting materials were obtained from commercial suppliers and used without further purification. Building blocks and final products were purified by column chromatography with 200-300 mesh silica gel. ${ }^{1} \mathrm{H}-\mathrm{NMR}$ spectra was measured by Bruker Avance $400 \mathrm{MHz}$ NMR Spectrometer with TMS as the internal standard and $\mathrm{CDCl}_{3}$ as solvent.

\section{General procedure for the synthesis of $3 a$ and $3 b$}

The saturated potassium carbonate aqueous solution ( $55 \mathrm{mmol} \mathrm{K} \mathrm{CO}_{3}$ ) was added to a well stirred solution of naphthalen-1-amine $(50 \mathrm{mmol})$ dissolved in $20 \mathrm{~mL}$ acetone and cooled to $0^{\circ} \mathrm{C}$. Chloroacetyl chloride $(55 \mathrm{mmol})$ was added dropwise. The mixture was slowly warmed to room temperature and stirred until the TLC analysis showed reaction endpoint. The mixture was extracted by ethyl acetate. The organic layer was combined, washed by saturated brine, dried over anhydrous $\mathrm{Na}_{2} \mathrm{SO}_{4}$, filtered, and concentrated to give compound $3 \mathrm{a}$ (white solid, 9.0 g, 81.9\%). The same method was used to synthesize $3 \mathrm{~b}$ (white solid, $7.9 \mathrm{~g}, 63.8 \%$ ).

\section{General procedure for the synthesis of $4 a$ and $4 b$}

A mixture of benzo[d]thiazole-2-thiol ( $5 \mathrm{mmol}), 3 \mathrm{a}$ (or $3 b)(5 \mathrm{mmol}), \mathrm{K}_{2} \mathrm{CO}_{3}(5.5 \mathrm{mmol})$, and $\mathrm{KI}(0.5 \mathrm{mmol})$ in $10 \mathrm{~mL}$ DMF was mixed and stirred at room temperature for $4 \mathrm{~h}$. At reaction endpoint, the mixture was extracted by ethyl acetate. The acetate extract was washed with saturated brine, dried over anhydrous $\mathrm{Na}_{2} \mathrm{SO}_{4}$, filtered, and concentrated. The residue was purified by silica gel column chromatography with petroleum ether: ethyl acetate $=7: 1-4: 1$ to obtain the target compound $4 a($ or $4 b)$. 


\section{Enzymatic assays}

Inhibitory activities of compounds $4 \mathrm{a}$ and $4 \mathrm{~b}$ on PTP-MEG2, Protein tyrosine phosphatase 1B (PTP1B) and $\mathrm{T}$ cell protein tyrosine phosphatase (TCPTP) were performed with pNPP (Para-Nitro Phenyl Phosphate) as the substrate. Briefly, pNPP was hydrolyzed by PTPs to give para-nitrophenol. Para-nitrophenol converts into paranitrophenolate (pNP), measured with a spectrophotometer after stopping solution was added. The regents and chemicals used in this assay are as follows: Ni-NTA labeled human recombinant PTPs expressed in E coli; dephosphorylation assay buffer ( $50 \mathrm{mM}$ citrate $(\mathrm{pH} 6.0), 0.1$ $\mathrm{M} \mathrm{NaCl}, 1 \mathrm{mM}$ EDTA and $1 \mathrm{mM}$ dithiothreitol (DTT)); substrate ( $2 \mathrm{mM}$ pNPP) in assay buffer; stopping solution ( $0.2 \mathrm{M}$ sodium hydroxide). PTPs and test-compounds with geometrically increasing concentrations were mixed in 50 $\mu \mathrm{L}$ buffer in each well of a 96-well plate. An equivalent volume of buffer without PTPs was used as blank control. After pre-incubation for $15 \mathrm{~min}$ at room temperature, the substrate $(50 \mu \mathrm{L})$ was added into each well and incubated at $37^{\circ} \mathrm{C}$ for $30 \mathrm{~min}$. Stopping buffer was poured into each well on ice and the OD value was read at $405 \mathrm{~nm}$ against blank.

\section{Drug-protein interaction study}

The interaction between compound 4a and PTPMEG2 was predicted by Glide 5.0 of Schrodinger 2012, a commonly used method for docking studies. Crystal structure of PTP-MEG2 (PDB ID: 4GE6) was downloaded from the PDB bank. As a potential inhibitor against PTPMEG2, compound $4 \mathrm{a}$ was prepared in silicon via the ligand structure preparation module "LigPrep". Docking site was determined by original ligand of PTP-MEG2 in its crystal structure.

\section{Molecular dynamics simulation}

Molecular dynamics simulation is a tool used to study the interaction between small molecules and proteins. In this study, we combined the static structures and dynamic information to investigate the binding mode and affinity between PTP-MEG2 and its inhibitors. We used GROMACS 4.5 [20] for Linux for molecular dynamics simulation.

The topology file, partial charges and force field parameters for ligand atoms were generated by the Dundee PRODRG 2.5 Server (University of Dundee, Dundee, Scotland) (beta)[21]. Taking PTP-MEG2 as an example, the simulation system was solvated in a specific box with SPC water solute $[22,23]$ and sodium and chloride ions were added into the system to neutralize redundant charges. Steepest descents approach was used to minimize energy for the system until reaching a tolerance of $100 \mathrm{kcal} / \mathrm{mol}$. A $40 \mathrm{~ns}$ molecular dynamics simulation $[24,25]$ was performed with a time step of 1 fs, and the corresponding coordinates were stored every 100 fs. All simulations were performed under constant temperature $(310 \mathrm{~K})$, periodic boundary conditions and NVT ensembles.

\section{ACKNOWLEDGMENTS}

This work was supported by grant (No. 81273361) from the National Science Foundation of China (NSFC), grant (No. 20121202120010) from New Teacher of Doctor Station of China and China postdoctoral Science Foundation (2016M591397). We thank Dr. Austin Cape at ASJ Editors for careful review and suggestions.

\section{CONFLICTS OF INTERESTS}

The Authors do not have any conflicts of interest.

\section{REFERENCES}

1. Hunter T. Protein kinases and phosphatases: the yin and yang of protein phosphorylation and signaling. Cell. 1995; 80(2):225-236.

2. Li XB, Wang SQ, Xu WR, Wang RL and Chou KC. Novel inhibitor design for hemagglutinin against H1N1 influenza virus by core hopping method. PloS one. 2011; 6(11):e28111.

3. Tonks NK and Neel BG. Combinatorial control of the specificity of protein tyrosine phosphatases. Current opinion in cell biology. 2001; 13(2):182-195.

4. Zhang ZY. Protein tyrosine phosphatases: prospects for therapeutics. Current opinion in chemical biology. 2001; 5(4):416-423.

5. Aravind L, Neuwald AF and Ponting CP. Sec14p-like domains in NF1 and Dbl-like proteins indicate lipid regulation of Ras and Rho signaling. Curr Biol. 1999; 9(6):R195-197.

6. $\mathrm{Gu}$ M, Warshawsky I and Majerus PW. Cloning and expression of a cytosolic megakaryocyte protein-tyrosinephosphatase with sequence homology to retinaldehydebinding protein and yeast SEC14p. Proceedings of the National Academy of Sciences of the United States of America. 1992; 89(7):2980-2984.

7. Cho CY, Koo SH, Wang Y, Callaway S, Hedrick S, Mak PA, Orth AP, Peters EC, Saez E, Montminy M, Schultz PG and Chanda SK. Identification of the tyrosine phosphatase PTP-MEG2 as an antagonist of hepatic insulin signaling. Cell metabolism. 2006; 3(5):367-378.

8. Iversen LF, Moller KB, Pedersen AK, Peters GH, Petersen AS, Andersen HS, Branner S, Mortensen SB and Moller NP. Structure determination of $\mathrm{T}$ cell protein-tyrosine 
phosphatase. J Biol Chem. 2002; 277(22):19982-19990.

9. Zhang S and Zhang ZY. PTP1B as a drug target: recent developments in PTP1B inhibitor discovery. Drug Discov Today. 2007; 12(9-10):373-381.

10. Zhang S, Liu S, Tao R, Wei D, Chen L, Shen W, Yu ZH, Wang L, Jones DR, Dong XC and Zhang ZY. A highly selective and potent PTP-MEG2 inhibitor with therapeutic potential for type 2 diabetes. Journal of the American Chemical Society. 2012; 134(43):18116-18124.

11. Berman HM, Battistuz T, Bhat TN, Bluhm WF, Bourne PE, Burkhardt K, Feng Z, Gilliland GL, Iype L, Jain S, Fagan P, Marvin J, Padilla D, et al. The Protein Data Bank. Acta crystallographica Section D, Biological crystallography. 2002; 58(Pt 6 No 1):899-907.

12. Westbrook J, Feng Z, Jain S, Bhat TN, Thanki N, Ravichandran V, Gilliland GL, Bluhm W, Weissig H, Greer DS, Bourne PE and Berman HM. The Protein Data Bank: unifying the archive. Nucleic acids research. 2002; 30(1):245-248.

13. CombiGlide2.5. New York, NY: Schrödinger LLC. 2009.

14. Fischer EH, Charbonneau H and Tonks NK. Protein tyrosine phosphatases: a diverse family of intracellular and transmembrane enzymes. Science. 1991; 253(5018):401406.

15. Irwin JJ and Shoichet BK. ZINC--a free database of commercially available compounds for virtual screening. Journal of chemical information and modeling. 2005; 45(1):177-182.

16. Eldridge MD, Murray CW, Auton TR, Paolini GV and Mee RP. Empirical scoring functions: I. The development of a fast empirical scoring function to estimate the binding affinity of ligands in receptor complexes. Journal of computer-aided molecular design. 1997; 11(5):425-445.

17. Halgren TA, Murphy RB, Friesner RA, Beard HS, Frye LL, Pollard WT and Banks JL. Glide: a new approach for rapid, accurate docking and scoring. 2. Enrichment factors in database screening. Journal of medicinal chemistry. 2004; 47(7):1750-1759.
18. Jorgensen WL and Duffy EM. Prediction of drug solubility from structure. Advanced drug delivery reviews. 2002; 54(3):355-366.

19. Singh Kh D, Kirubakaran P, Nagarajan S, Sakkiah S, Muthusamy K, Velmurgan D and Jeyakanthan J. Homology modeling, molecular dynamics, e-pharmacophore mapping and docking study of Chikungunya virus nsP2 protease. Journal of molecular modeling. 2012; 18(1):39-51.

20. Housaindokht MR, Bozorgmehr M and Bahrololoom M. Analysis of ligand binding to proteins using molecular dynamics simulations. J Theor Biol. 2008; 254(2):294-300.

21. Schuttelkopf AW and van Aalten DM. PRODRG: a tool for high-throughput crystallography of protein-ligand complexes. Acta crystallographica Section D, Biological crystallography. 2004; 60(Pt 8):1355-1363.

22. Starr FW, Nielsen JK and Stanley HE. Hydrogen-bond dynamics for the extended simple point-charge model of water. Physical review E, Statistical physics, plasmas, fluids, and related interdisciplinary topics. 2000; 62(1 Pt A):579-587.

23. Wu Y, Tepper HL and Voth GA. Flexible simple pointcharge water model with improved liquid-state properties. The Journal of chemical physics. 2006; 124(2):024503.

24. Gharaghani S, Khayamian $\mathrm{T}$ and Keshavarz F. Docking, molecular dynamics simulation studies, and structure-based QSAR model on cytochrome P450 2A6 inhibitors. Struct Chem. 2012; 23(2):341-350.

25. Lei B, Adel H and Zhan C-G. Structural features and binding free energies for non-covalent inhibitors interacting with immunoproteasome by molecular modeling and dynamics simulations. Theor Chem Acc. 2012; 131(4):1-11. 